\section{C-peptide measurement in the differentiation of Type 1 and Type 2 diabetes mellitus - correction and comment}

\section{Dear Sir, \\ The recent paper entitled " $\mathrm{C}$-peptide measurement in the differ-} entiation of Type 1 (insulin-dependent) and Type 2 (non-insulin-dependent) diabetes mellitus" by Katzeff et al. [1] has some calculation errors and statistical findings which warrant a comment.

The authors report (lines 10-14, second paragraph in the second column of p.266) that "Both fasting C-peptide and urinary C-peptide excretions were positively correlated with body mass index in Pima Indians $(r=0.56, p<0.05$ and $0.77, p<0.05$, respectively)". However, for the same number of subjects, they report in the succeeding paragraph that "Urinary excretion of $\mathrm{C}$-peptide tended to be lower with increasing duration of diabetes mellitus in both groups (Pima $r=-0.65, p \approx 0.05$; Caucasoids $-0.58, p>0.05$ )". I have recalculated the $r$ values and found that the body mass index had nonsignificant correlations with basal C-peptide $(r=0.35, p>0.05$ in stead of $0.56, p<0.05)$ and with urinary C-peptide $(r=0.57, p>0.05$ instead of $0.77, p<0.05$ ). For the number of subjects all their " $\mathrm{r}$ " values, including that of -0.65 , were without statistical significance. The authors pointed out rightly in their discussion the limitations of the small numbers. However, I wish to emphasise in addition the limitations imposed by the selectivity of various study populations, especially those which are carefully chosen. Thus, in this small group of Pima Indians, it is possible that the contribution from insulin resistance associated with obesity masked the effect of the duration of the disease on the urinary C-peptide levels. To examine this hypothesis I calculated the correlation coefficient between body mass index and duration of diabetes $(r=-0.085)$, and then used the formula of the partial correlation [2]. When the contribution of the body mass index was held constant, the inverse relationship between the duration and urinary C-peptide became statistically significant $(r=-0.73, p<0.05$ ). Likewise, when the contribution from the duration was held constant, the positive association between obesity and urinary C-peptide became much stronger $(r=0.68)$.

Further analysis of their data revealed that the prevalence of HLA B8 in their Caucasoid patients was $78 \%$ ( 7 of 9 subjects) and that of islet cell antibodies was $83 \%$ ( 5 of 6 subjects). It is doubtful that this group could be considered representative of Caucasoid Type 1 diabetic patients. Hence it was not surprising to find that Fisher's Exact Test yielded statistically significant differences between Caucasoid Type 1 and Pima Indian Type 2 patients which were much higher than those observed by the authors $(p<0.002$ for HLA B 8 instead of $p<0.05$, and $p<0.004$ for islet cell antibodies instead of $p<0.05$ ).

It is more than likely that $\mathrm{C}$-peptide levels in patients with diabetes mellitus will be found in a form of a spectrum. Low levels are expected in those with destruction of the $\mathrm{B}$ cell or those with long duration of the disease. It is hoped that more data on C-peptide levels in non-carefully selected and larger groups of patients will become available. In the meantime, the clinical response to insulin therapy, either acutely (as in patients with ketoacidosis) or less acutely (as in the non-obese "Type 2" patient with weight loss), should not be undermined by the "diagnostic usefulness" of C-peptide assays.

Yours sincerely,

W. A. Luqman

\section{References}

1. Katzeff HL, Savage PJ, Barclay-White B, Nagulesparan M, Bennett PH (1985) C-peptide measurement in the differentiation of Type 1 (insulin-dependent) and Type 2 (non-insulin-dependent) diabetes mellitus. Diabetologia 28: 264-268

2. Daniel WW (1978) Multiple regression and correlation. In: Da niel WW (ed) Biostatistics, a foundation for analysis in the health sciences, 2nd edn. Wiley, New York Chichester Brisbane pp 304-337

Dr. Wijdan A. Luqman

Veterans Administration Medical Center

Asheville, NC 28805

USA

\section{Response from the authors}

Dear Sir,

I apologize for the error which occurred in our paper [1] and thank Dr. Luqman for pointing out that we incorrectly reported the values of two correlation coefficients. As Dr. Luqman calculated, the correlations for plasma and urinary C-peptide with body mass index in the Pima Indian should have been 0.35 and $0.57(p>0.05)$, respectively.

As stated in the paper, the urinary C-peptide excretion did tend to be lower with increasing duration of diabetes in the Pima ( $r=-0.65, p \simeq 0.05$ ), the critical $r$ value at $5 \%$ level of significance being -0.67 . However, as Dr. Luqman showed by calculating partial correlation coefficients, the correlation does tend to be stronger $(-0.73)$ if body mass index is held constant (critical value for $r$ at $5 \%=0.71$ for partial correlation). The correlation between urinary Cpeptide and body mass index $(0.57)$ is also strengthened slightly $(0.68)$ when duration is held constant. We agree with Dr. Luqman, therefore, that the negative correlation between C-peptide levels and duration do "suggest that insulin output falls with increasing duration in both Type 2 and Type 1 diabetes, although longitudinal data are needed to validate the observation" [1]. More extensive (and prospective) data on representative groups of patients are clearly desirable and necessary to establish this.

No particular significance can be placed on the level of the estimate of $p$ for differences in HLA-B8 and islet cell antibody frequencies between Caucasoid and the Pima groups, except that it is un- 
likely that they are drawn from the same population. Such small samples cannot be expected to be truly representative; as we stated in Methods, the group of Caucasoids in the study "were assumed almost certainly to have Type 1 diabetes." The certainty would have been greater if all had HLA-B8 and/or islet cell antibodies.

In view of our results I do believe, however, that C-peptide levels can be useful, particularly for research purposes. They facilitate the correct classification of insulin-treated patients, which clinically might prevent unnecessary or inappropriate withdrawal of insulin treatment.

Yours sincerely,

P.H. Bennett

\section{Reference}

1. Katzeff HL, Savage PJ, Barclay-White B, Nagulesparan M, Bennett PH (1985) C-peptide measurement in the differentiation of Type 1 (insulin-dependent) and Type 2 (non-insulin-dependent) diabetes mellitus. Diabetologia 28: 264-268

\section{Dr. Peter H. Bennett}

Department of Health and Human Services

National Institute of Diabetes

and Digestive and Kidney Diseases

Bethesda, MD 20892

USA

\section{Book review}

Clinical diabetes mellitus: a problem orientated approach. J. K. Davidson (ed) Thieme, Stuttgart 1986, Hardback, DM 298.-

Dr. Davidson has, by word and example, been a prime mover in steering diabetologists away from the teaching hospital model of acute care which emphasises episodic crisis intervention but neglects organised long-term care and prevention. His premise is that "No single health care professional possesses all the resources and skills to provide comprehensive care to the individual with diabetes"; he therefore took the logical step of forming a multi-disciplinary team. This mammoth book - 666 pages provided by 75 contributors - emphasises team care and is described as "An attempt to consolidate and index contemporary knowledge of diabetes so that it will be quickly available to practicing physicians and other health care professionals". I sympathise with these aims, but have reservations about how far the book succeeds in fulfilling them. The advertisement describes the book as "The only text that features a problem orientated format - and consequently - it's the only text that provides easy access to clinical information on all aspects of diagnosis, treatment and current research of diabetes mellitus. You'll find direct solutions to the problems you face daily". I cannot make the leap of faith to become a wholesale convert to the Problem Orientated Medical Record (POMR) - which is used in all the chapters written by Dr. Davidson and his close collaborators but (very noticeably) by virtually none of the authors who hail from outside Atlanta. In theory, POMR should promote understanding between members of a team and allow everyone (including the patient if he is given a copy of the record) to have a clear view of the problems and future plans. This might be true if all it involved was a simple problem list; however, when it is expanded into a problem statement with the sub-headings "Subjective, Objective, Assessment and Plan", all I find it does is to make clinical medicine needlessly complicated. I would expect most readers to recoil in horror when confronted by the standard forms for initial assessment (appendix 6) which contain nearly 100 main headings, most of which have up to 6 further sub-divisions. Even the editor sometimes fails to follow the POMR format; for example, the case history of an non-adherent patient (page 161) includes no social history and no positive suggestion on what to do with the identified problem of "Compulsive eating which appeared to be an integral part of her life style". The detail expected in collecting a comprehensive data base is sometimes breath-taking. For example, the objective part of the data base for Type 2 (non-insulin-dependent) diabetes includes: "Determine patient's weight, (pounds or kilograms), height (inches or centimetres) frame (wrist circumference, finger size, elbow breadth), adiposity (skin fold thickness, body specific gravity measured by underwater weighing, palpation of abdomen and other parts of the body to estimate amount of adiposity)". Even if one had time to collect this sort of information and weigh one's patients under water, I cannot see how one would use it. It is in stark contrast to the statement a few pages earlier that "Medical education is wrong in that it emphasises data acquisition rather than problem solving". This book does, in fact, contain an enormous amount of information, and anyone who takes the trouble to read it from cover to cover will undoubtedly learn a great deal about diabetes. I liked the format whereby each chapter contains a historical perspective, a section on epidemiology, one on pathophysiology and ends up with the author's summary of current and future research. Nevertheless, I doubt whether it provides any easier access to clinical information than other comparably sized text books in a standard format. The printing is of a very high standard and the book is profusely illustrated with photographs, diagrams and tables.

R. Tattersall (Nottingham)

\section{Announcement}

Post-EASD International Symposium on Diabetes Secondary to Pancreatopathy

This Symposium will take place in Padova, Italy, from 21-22 September 1987. The Symposium will consist of plenary lectures, round tables and free-presentations explaining the hormonal, metabolic and clinical aspects of diabetes secondary to pancreatitis and pancreatectomy. All correspondence regarding guidelines and general information should be addressed to: Antonio Tiengo, M.D. and Stefano Del Prato, M.D., Cattedra di Malattie del Ricambio, via Giustiniani 2, I-35100 Padova, Italy.

\section{Erratum}

Diabetologia, Volume 30, Number 3, March 1987, pp. 123-131

G. Panzram: Mortality and survival in Type 2 (non-insulin-dependent) diabetes mellitus

p. 129: please note that in the section 'Concluding remarks' the second sentence should read

'There is conclusive evidence that atherosclerosis and Type 2 diabetes develop coincidentally, in parallel, or even in reversed sequence: 